\title{
Robert Birkholc
}

(Warszawa)

\section{NARRACJA SUBIEKTYWNA ZAPOŚREDNICZONA. WOKÓ Z ZAGADNIENIA „MOWY POZORNIE ZALEŻNEJ” W FILMIE}

\section{Abstract}

The paper sets out to describe the "free indirect speech" of film, which the author chooses to call "mediated subjective narrative". Based on specific examples, the author characterizes the narrative devices which in a way are analogous to what literary studies define as "free indirect discourse". The basic indicators of that textual figure include subjectivization of communication on a stylistic level and interference of internal and external focalization.

\section{Key words}

mediated subjective narrative, free indirect speech, film narrative, focalization 


\section{KATEGORIA „MOWY POZORNIE ZALEŹNEJ” W TEORII FILMU}

Według literaturoznawczych definicji mowa pozornie zależna ${ }^{1}$ oznacza typ wypowiedzi, w której narrator posługuje się mową bohatera, ale nie stosuje żadnych znaków demarkacyjnych odgraniczających przytaczaną wypowiedź od swojej własnej. Tym samym różni się ona od mowy niezależnej (kiedy narrator bezpośrednio przytacza wypowiedź bohatera) oraz od mowy zależnej (kiedy narrator relacjonuje wypowiedź bohatera, używając własnych słów). Choć kategoria ta była adaptowana na grunt teorii filmu już od lat 60 . XX w., do dziś nie doczekała się monografii filmoznawczej i bywa pomijana w słownikach i encyklopediach kina. Audiowizualna "mowa pozornie zależna" była zazwyczaj rozumiana $w$ sposób metaforyczny, jako kategoria pozwalająca mówić o pewnych zagadnieniach narracji filmowej, ale niedająca się sprecyzować na gruncie kina, ponieważ związana źródłowo z innym medium. Brak ścisłej definicji oraz naukowego opisu doprowadził do sytuacji, w której niemal każdy $\mathrm{z}$ teoretyków interpretował to pojęcie odmiennie. Przedstawienie spójnej koncepcji badawczej mogłoby nie tylko pomóc w uporządkowaniu metodologicznego chaosu, lecz także rzucić nowe światło na zagadnienie reprezentacji subiektywności w filmie, wbrew pozorom nieopisane dotychczas w sposób wyczerpujący. Istnieją dwa podstawowe warunki takich komparatystycznych badań. Po pierwsze powinny one uwzględniać literackie wyznaczniki kategorii tak, aby mówienie o tekstowej analogii miało rację bytu. Po drugie nie mogą opierać się na bezrefleksyjnym przenoszeniu pojęcia $z$ literaturoznawstwa do filmoznawstwa, lecz muszą uwzględniać specyfikę języka ruchomych obrazów. Doskonałych narzędzi do komparatystycznych badań dostarcza narratologia transmedialna, dziedzina, która nie była jeszcze dobrze rozwinięta, kiedy powstawały pierwsze (i w dalszym ciągu najbardziej wpływowe) koncepcje filmowej „mowy pozornie zależnej”.

Opierając się na konkretnych przykładach filmowych, postaram się scharakteryzować zabiegi narracyjne, które są $\mathrm{w}$ pewien sposób analogiczne do tego, co w literaturoznawstwie określa się mianem mowy pozornie zależnej. Rozpoznania te nie tyle mają udowodnić, że możliwa jest adaptacja tej kategorii $z$ jednej dziedziny do drugiej, ile wykazać, że istnieje pewna trans-

\footnotetext{
${ }^{1}$ Polskiej „mowie pozornie zależnej” $\mathrm{w}$ mniejszym lub większym stopniu odpowiadają francuskie kategorie le style indirect libre i discourse indirect libre, angielskie free indirect speech, substitutionary narration i narrated monologue oraz niemieckie erlebte Rede.
} 
medialna figura tekstowa, której cechą dystynktywną jest określony sposób uobecniania percepcji oraz świadomości bohatera w narracji. Proponuję wyróżnić dwie cechy tej figury - na tyle szczegółowe, by mogły uchwycić jej funkcję i na tyle ogólne, by znalazły odpowiedniki w różnych mediach. Wyznacznikami tymi są: 1) subiektywizacja przekazu na poziomie stylistycznym oraz 2) interferencja fokalizacji zewnętrznej i fokalizacji wewnętrznej.

Badacze piszący o „mowie pozornie zależnej” w filmie rzadko uwzględniali sformułowane na gruncie teorii literatury wyznaczniki tej kategorii. Jedną z pierwszych propozycji przedstawił w $1961 \mathrm{r}$. Jerzy Płażewski ${ }^{2}$. Autor "Języka filmu" stosuje pojęcie narracji pozornie zależnej w odniesieniu do dzieł filmowych, w których obiektywna narracja jest przeplatana relacjami poszczególnych bohaterów, tak jak ma to miejsce np. w „Obywatelu Kane” Orsona Wellesa. Trudno obronić tę koncepcję, ponieważ podobny zabieg ma niewiele wspólnego $\mathrm{z}$ literacką mową pozornie zależną - polega on na wprowadzeniu w obręb dzieła „bohaterów-narratorów”, postaci opowiadających historie, które są wizualizowane. Ponadto polski filmoznawca włącza w obręb "narracji pozornie zależnej” werbalne monologi wewnętrzne, sceny wizualizujące subiektywne przypuszczenia bohatera na temat przyszłości lub jego kłamstwa, a także reprezentacje stanów psychicznych - snów, halucynacji, itd. Płażewski próbuje objąć wspólnym terminem „narracja pozornie zależna" szereg zjawisk, które $\mathrm{z}$ narratologicznego punktu widzenia różnią się w sposób fundamentalny.

Najsłynniejszą koncepcję filmowej „mowy pozornie zależnej” przedstawił w latach 60. Pier Paolo Pasolini. W literackiej mowie pozornie zależnej, pisze Pasolini, „twórca zanurza się w duszy stworzonej przez siebie postaci, a za co tym idzie (...) przyswaja on nie tylko jej psychologię, ale także jej język”3. Reżyser nie ma możliwości, by odtworzyć indywidualną i społeczną różnicę zawartą $w$ języku werbalnym, ale może oddać subiektywne doświadczenie bohatera za pomocą środków stylistycznych. Właśnie w szczególnej stylistyce Pasolini widzi filmowe realizacje mowy pozornie zależnej, które nazywa „pozornie zależnymi ujęciami subiektywnymi” (soggettiva libera indiretta ${ }^{A}$ ). W filmach takich twórców, jak Michelangelo Antonioni, Bernardo Bertolucci czy Jean-Luc Godard - twierdzi włoski twórca i teoretyk - występuje swoiste napięcie pomiędzy punktem widzenia bohaterów a wizją samych reżyserów,

\footnotetext{
${ }^{2}$ J. Płażewski, Język filmu, Warszawa 2008, s. 293-300.

${ }^{3}$ P.P. Pasolini, Kino poezji, przeł. M. Salwa, [w:] M. Werner (red.), P.P. Pasolini, Po ludobójstwie. Esej o języku, polityce i kinie, Warszawa 2012, s. 158.

${ }^{4}$ Ibidem, s. 160.
} 
którzy, reprezentując doświadczenie postaci, dają jednocześnie wyraz własnym niepokojom i estetycznym upodobaniom. Badacz zakłada, że filmowa „mowa pozornie zależna" ma sens jedynie wtedy, gdy twórca zajmuje podobną pozycję społeczną, co bohater. W przeciwnym razie artysta narzuca postaciom własną wizję świata, mitologizuje je i asymiluje ich społeczną innośćs. $\mathrm{Z}$ epistemologicznym sceptycyzmem Pasoliniego można jednak polemizować. Dla widza nie ma znaczenia, czy pomiędzy reżyserem a bohaterem istnieje różnica społeczna, ponieważ liczy się przede wszystkim kreacja tekstowa. Eseistyczne rozważania włoskiego reżysera są uwikłane $\mathrm{w}$ marksistowską krytykę ideologiczną oraz $\mathrm{w}$ teorię kina autorskiego i nie dają się w całości przenieść na grunt narratologii. Pasolini próbuje nie tyle sprecyzować, czym jest „mowa pozornie zależna” w filmie (choć od takich rozważań wychodzi), ile określić, w jakim kierunku zmierza nowoczesne kino artystyczne.

Koncepcja Pasoliniego doczekała się bardzo interesującego rozwinięcia, a zarazem modyfikacji ${ }^{6}$. Gilles Deleuze w słynnym dziele „Kino. ObrazRuch" pisze o „mowie pozornie zależnej” w filmie jako szczególnej figurze, dzięki której zostaje załamana charakterystyczna dla kina klasycznego opozycja między tym, co obiektywne, a tym, co subiektywne. Tradycyjnie w filmie wszelka subiektywność była brana niejako w cudzysłów, traktowana jedynie jako zniekształcenie zewnętrznego, uprzywilejowanego spojrzenia obiektywnego. Kiedy w kinie klasycznym widzimy nieostry obraz oddający percepcję pijanego mężczyzny, od razu przyjmujemy, że jest to wizja zdeformowana i zakładamy, że z zewnętrznego punktu widzenia świat przedstawiony prezentuje się inaczej. Granica między tym, co subiektywne, a tym, co obiektywne dość problematyczna $w$ kinie $z$ uwagi na specyfikę tego medium - zostaje całkowicie zatarta dzięki zastosowaniu „mowy pozornie zależnej”. Według interpretacji Deleuze'a podmiot w „mowie pozornie zależnej” nie jest traktowany, jakby istniał niezależnie od narracji, jest dopiero wytwarzany $\mathrm{w}$ formie filmowej ${ }^{7}$. Rozpoznania te stanowią niewątpliwie bardzo interesujące filozoficzne podłoże do refleksji nad filmową „mową pozornie zależną”, ale dalekie są od narratologicznej precyzji ${ }^{8}$. W ujęciu Deleuze'a figury tej można szukać

\footnotetext{
${ }^{5}$ Ibidem, s. 174.

${ }^{6}$ Różnice pomiędzy ujęciami Pasoliniego i Deleuze'a analizuje Louis-Georges Schwartz: L.-G. Schwartz, Typewriter: free indirect discourse in Deleuze's Cinema, SubStance 3 (34), 2005.

${ }^{7}$ G. Deleuze, Kino. Obraz-ruch. Obraz-czas, przeł. J. Margański, Gdańsk 2008, s. 86.

${ }^{8}$ Oczywiście celem Deleuze'a nie było stworzenie narratologicznego modelu. Można wręcz powiedzieć, że Deleuzjańska teoria kina sytuuje się na przeciwległym biegunie, co badania narratologiczne. Jak piszą autorzy książki „Teoria filmu: Wprowadzenie przez zmysły”, kino nie jest dla francuskiego poststrukturalisty „medium, służącym do przekazywania opowieści, w których świat
} 
zarówno u Godarda, jak i u Erica Rohmera, mimo że obaj reżyserzy posługują się zupełnie odmiennymi trybami narracji. W rozważaniach francuskiego poststrukturalisty została znakomicie uchwycona przemiana zachodząca w modernistycznym kinie, ale sama kategoria "mowy pozornie zależnej” rozmywa się, stanowi jedynie pretekst do opisania bardziej ogólnych procesów, polegających na „uwolnieniu” obrazu filmowego od konieczności ilustrowania autorytatywnych znaczeń i reprodukowania uproszczonego modelu rzeczywistości.

\section{METODOLOGIA BADAŃ}

Refleksję nad funkcjonowaniem „mowy pozornie zależnej” w filmie trzeba rozpocząć od weryfikacji samej nazwy. Pojęcie „filmowa mowa pozornie zależna" - jeśli przyjąć, że nie dotyczy jedynie wygłaszanego w filmie werbalnego komentarza, ale wszystkich elementów wielosemiotycznego przekazu audiowizualnego - jest oparte na metaforze i może wprowadzać w błąd. Nazwa "mowa pozornie zależna" nie jest zresztą całkiem ścisła także w odniesieniu do literatury: czasem przedmiotem tej figury tekstowej jest nie tyle mowa bohatera, ile jego myśli lub percepcja ${ }^{9}$. W związku $\mathrm{z}$ tym, że nazwa nie może zostać pomyślnie przeniesiona do badań nad filmem, proponuję wprowadzić nowe określenie - narracja subiektywna zapośredniczona. W filmoznawstwie pojęcie narracji subiektywnej często bywa używane niekonsekwentnie i obejmuje dwa rodzaje zjawisk: po pierwsze, wiąże się je z doświadczeniami psychologicznymi i percepcyjnymi bohatera, po drugie, odnosi do osobistego stylu reżyserów kina autorskiego. Obie te subiektywności diametralnie różnią się od siebie, dlatego będę używał pojęcia narracji subiektywnej jedynie w pierwszym znaczeniu. Drugi człon nazwy - „zapośredniczona” - wskazuje na to, że narracja tego typu nie tworzy iluzji bezpośredniego dostępu do świata wewnętrznego bohaterów, lecz uwydatnia mediację innego podmiotu w przekazywaniu stanów wewnętrznych postaci.

Aby opisać podobieństwa i różnice pomiędzy literacką mową pozornie zależną a filmową narracją subiektywną zapośredniczoną, należy ustalić wspólny dla obydwu mediów aparat pojęciowy. W filmie można wyróżnić

jawi się uporządkowany przez narrację, jak wierzyli narratolodzy”. T. Elsaesser, M. Hagener, Teoria filmu: Wprowadzenie przez zmysły, przet. K. Wojnowski, Kraków 2015, s. 209.

${ }^{9}$ Zob. P. Hernadi, Dual Perspective: Free Indirect Discourse and Related Techniques, Comparative Literature 24, 1, 1972, s. 32-43. 
takie instancje jak „narrator” czy „fokalizator”, ale trzeba pamiętać, że funkcjonują one $w$ inny sposób niż w literaturze ${ }^{10}$. Narrator filmowy, rozumiany jako podmiot tekstowy, który za pomocą obrazu i dźwięku przedstawia elementy fabuly ${ }^{11}$, nigdy nie jest spersonalizowany. Aktywność tej bezosobowej instancji przejawia się we wszystkich elementach, które składają się na narrację filmową: w montażu, pracy kamery, podkładzie dźwiękowym etc. Trzeba jednak pamiętać, że te określenia są czysto techniczne i odnoszą się do poziomu zewnątrztekstowego, podczas gdy narrator jest instancją wewnątrztekstową i nie należy go utożsamiać $\mathrm{z}$ żadnym $\mathrm{z}$ twórców filmu.

Ponadto w filmie można wyróżnić instancję „bohatera-narratora”, będącego podmiotem - werbalnej, niewerbalnej albo $i$ takiej, $i$ takiej - narracji. $\mathrm{Z}$ pierwszą sytuacją mamy do czynienia, gdy słyszymy opowieść postaci, $z$ drugą, kiedy opowieść ta zostaje zwizualizowana i tworzy odrębny poziom narracyjny. Problem w tym, że „bohater-narrator” w kinie - inaczej niż w literaturze, gdzie jest „wytwórcą" werbalnego przekazu - nie odpowiada za wytwarzanie wizualnych znaków ${ }^{12}$, a jego opowieść zawsze jest przedstawiana przez narratora zewnętrznego (ekstradiegetycznego). Właśnie dlatego nie można mówić o ścisłym odpowiedniku literackiej narracji pierwszoosobowej w kinie. Kompetencje narratora $w$ literaturze i $w$ filmie są na tyle odmienne, że utożsamienie tych instancji w badaniach komparatystycznych byłoby zbyt daleko idącym uproszczeniem. Narzędziem umożliwiającym porównanie literackiej mowy pozornie zależnej $z$ jej filmowym odpowiednikiem jest jednak nie kategoria narratora, ale fokalizatora, nie „opowiadacza”, ale „podmiotu percypującego".

Wprowadzone przez Gérarda Genette'a pojęcie fokalizacji oznacza perspektywę, w ramach której są przedstawiane elementy fabuły. Francuski badacz chciał zwrócić uwagę na to, że narracja często jest przedstawiana z punktu widzenia jednego $\mathrm{z}$ bohaterów i należy odróżniać podmiot wypowiadający

\footnotetext{
${ }^{10} \mathrm{~W}$ teorii filmu do dziś toczy się dyskusja dotycząca tego, czy zasadne jest wyróżnianie instancji narratora w filmie. Za szeregiem filmoznawców przyjmuję, że nie można mówić o narracji pozbawionej narratora, ponieważ sam akt narracji implikuje jego obecność. Zob. S. Chatman, Coming To Terms. The Rhetoric of Narrative in Fiction and Film, London 1990; T. Gunning, D.W. Griffith and the Origins of American Narrative Film: The Early Years at Biograph, Chicago 1991, s. 23-24; G. Wilson, Narration in Light, Studies in Cinematic Point of View, London 1992.

${ }^{11}$ Podobnie narratora definiuje Mieke Bal, pisząc o „agensie, który wytwarza (językowe lub inne) znaki konstytuujące tekst”. M. Bal, Narratologia. Wprowadzenie do teorii narracji, przekład zbiorowy, Kraków 2012, s. 18.

${ }^{12}$ Narracja werbalna „bohatera-narratora” $w$ filmie jest zbliżona do narracji narratora literackiego, jednak nie konstytuuje nigdy całości przekazu, ponieważ zawsze towarzyszą jej inne rodzaje znaków, związane $\mathrm{z}$ poziomem wizualnym narracji.
} 
(narratora) od podmiotu, którego percepcja jest werbalizowana ${ }^{13}$. Modyfikując pojęcie Genette'a, Mieke Bal stworzyła kategorię fokalizatora, podmiotu percypującego $\mathrm{w}$ tekście, który przefiltrowuje świat przedstawiony przez swoją świadomość i/lub wypełnia go danymi sensualnymi ${ }^{14}$. Zdaniem Bal fokalizacja to wewnątrztekstowa perspektywa, którą narrator przedstawia za pomocą określonego materiału semiotycznego. Wpisany w tekst „punkt widzenia" może przybierać różne formy: być ekstradiegetyczny (wtedy mamy do czynienia $\mathrm{z}$ fokalizacją zewnętrzną) albo intradiegetyczny (fokalizacja wewnętrzna, przypisana jednemu $z$ bohaterów), odseparowany od podmiotowości bohaterów albo posługujący się ich myśleniem oraz postrzeganiem świata. Pojęcie fokalizacji jest bardzo przydatne przy opisie narracji subiektywnej zapośredniczonej, w której najistotniejsza jest właśnie percepcja czy też świadomość zabarwiająca świat przedstawiony. Bohater filmowy nie może być narratorem sensu stricto, ponieważ nie włada językiem filmu ${ }^{15}$, ale bardzo często bywa fokalizatorem ${ }^{16}$. Podobnie jak w literaturze, perspektywa z której „ukazany” został świat diegetyczny, może należeć do jednej z postaci, być zewnętrzna wobec fabuły albo hybrydyczna. W przypadku narracji subiektywnej zapośredniczonej mamy do czynienia najczęściej z tym ostatnim przypadkiem, ponieważ wszelkie rozróżnienia pomiędzy zewnętrznymi i wewnętrznymi instancjami zostają zaburzone.

${ }^{13}$ G. Genette, Narrative Discourse. An Essay in Method, przeł. J.E. Lewin, New York 1980, s. $195-198$.

${ }^{14}$ Zob. M. Bal, Narratologia. Wprowadzenie do teorii narracji. Na temat fokalizacji w literaturze zob. m.in.: A. Lebkowska, Pojęcie fokus w narratologii - problemy i inspiracje, [w:] J. Bartmiński, S. Niebrzegowska-Bartmińska, R. Nycz (red.), Punkt widzenia w tekście i w dyskursie, Lublin 2004, s. 219-238; M. Jahn, Windows of Focalization: Deconstructing and Reconstructing a Narratological Concept, Style 30, 2, 1996, s. 241-267; H. Markiewicz, Teorie powieści za granicą, Warszawa 1995, s. 435-436; W. Michera, Piękna jako bestia. Przyczynek do teorii obrazu, Warszawa 2010, s. 115-142; W. Nelles, Getting Focalization into Focus, Poetics Today 2 (11), 1990, s. 365-382; M. Rembowska-Płuciennik, W cudzej skórze. Fokalizacja zmysłowa a literackie reprezentacje doświadczeń sensualnych, Ruch Literacki 6, 2006, s. 51-67.

${ }^{15}$ Mirosław Przylipiak pisze o głównej bohaterce Giulietty i duchów, postaci, której wyraźnie podporządkowana jest narracja filmowa: „Giulietta $z$ filmu Felliniego nie ma świadomości języka filmu (cokolwiek by to miało znaczyc) i nie jest jej intencją komukolwiek komunikować, co się wewnątrz niej dzieje”. M. Przylipiak, O subiektywizacji narracji filmowej, Studia Filmoznawcze VII, 1987, s. 247-248.

${ }^{16} \mathrm{Na}$ temat fokalizacji w filmie zob. m.in.: C. Deleyto, Focalisation in Film Narrative, Atlantis 13, 1-2, 1991, s. 159-177; P. Verstraten, Film Narratology, przeł. na ang. S. van der Lecq, Toronto 2009. 


\section{WYZNACZNIKI NARRACJI SUBIEKTYWNEJ ZAPOSREDNICZONEJ}

\subsection{SUBIEKTYWIZACJA PRZEKAZU NA POZIOMIE STYLISTYCZNYM}

Wypowiedź narratora $w$ literackiej mowie pozornie zależnej jest ukształtowana pod względem stylistycznym tak, by odbiorca odnosił wrażenie, że elementy świata przedstawionego zostały przefiltrowane przez świadomość lub percepcję postaci. Właśnie dzięki owej subiektywizacji mowa pozornie zależna odegrała ogromną rolę w rozwoju powieści w drugiej połowie XIX i na początku XX w. Wykorzystanie tej figury narracyjnej w dziełach takich autorów jak Henry James, Jane Austen czy - nieco później - Virginia Woolf, wiązało się $\mathrm{z}$ detronizacją monofonicznego, wszechwiedzącego narratora auktorialnego. Do narracji zaczęły przenikać mowa i myśli postaci, dzięki czemu przekaz werbalny stał się silnie zsubiektywizowany, a horyzont myślowy - zrelatywizowany, związany $\mathrm{z}$ jednostkowymi punktami widzenia. Modelowym przykładem powieści, której narracja ukształtowana została przez mowę pozornie zależną, jest „Pani Dalloway”. Narracja nieustannie "przeskakuje" w utworze Woolf od jednej wewnątrzfabularnej świadomości do drugiej, a świat przedstawiony ukazywany jest niemal wyłącznie poprzez myśli bohaterów.

Poczynając od niemieckiego ekspresjonizmu filmowego a na postmodernistycznych „narracjach schizofrenicznych" kończąc, w historii kina można odnaleźć ogromną liczbę dzieł, gdzie postać stanowi centrum świadomości, wokół którego rozwija się narracja. Nie w każdym przypadku zachodzi jednak subiektywizacja stylistyczna. Czytelnik odbiera mowę pozornie zależną jako subiektywną dzięki temu, że w obręb wypowiedzi narratora zostały włączone elementy stylu językowego, który może odsyłać do języka którejś z postaci. Pojawienie się elementów nacechowanych stylistycznie ${ }^{17}$ jest również warunkiem zaistnienia narracji subiektywnej zapośredniczonej - na wewnętrzną perspektywę bohatera wskazuje tu jednak nie tyle słowo, ile szereg innych, wizualnych i dźwiękowych środków narracyjnych, takich jak punkty widzenia kamery, oświetlenie, inscenizacja, kolory, montaż, muzyka, etc. Narracja ta nie polega na wizualizacji tego, co bohater zobaczył lub sobie

\footnotetext{
${ }^{17}$ Przez nacechowanie stylistyczne rozumiem naruszenie norm „stylu zerowego”, czyli takie ukształtowanie narracji, które wskazuje na jej „nieprzezroczystośc”. Na temat kina stylu zerowego zob.: M. Przylipiak, Kino stylu zerowego, Gdańsk 1994.
} 
wyobraził, lecz na reprezentacji subiektywnego - zdeterminowanego przez emocje, pragnienia, zmysły - sposobu doświadczania przez niego rzeczywistości.

Przedmiot i zakres subiektywizacji mogą być różne: czasem chodzi o odtworzenie nastroju i stanu emocjonalnego postaci (jak w „Niebieskim” Krzysztofa Kieślowskiego), kiedy indziej o symulację sposobu postrzegania rzeczywistości (jak w „Palaczu zwłok” Juraja Herza). Warto przyjrzeć się, w jaki sposób efekt subiektywizacji budowany jest w „Tańczącym jastrzębiu” (1977) Grzegorza Królikiewicza. Bohaterem adaptacji powieści Juliana Kawalca jest Michał Toporny (Franciszek Trzeciak), chłop, który po drugiej wojnie światowej robi urzędniczą karierę w mieście. Alienacja, strach i poczucie niedopasowania bohatera do nowej roli społecznej znajdują odzwierciedlenie w szeregu elementów narracyjnych: w zniekształceniach perspektywicznych, w przybierającej niekiedy groteskowe formy scenografii, w nerwowych ruchach oraz niestandardowych punktach widzenia kamery, a także w ekspresyjnej ścieżce dźwiękowej, wypełnionej nienaturalnie donośnymi odgłosami. Widz nieustannie odnosi wrażenie, że percepcja Topornego „zabarwia” narrację filmową. Środki narracyjne tworzą imitację sposobu postrzegania rzeczywistości przez mężczyznę. Subiektywna perspektywa postaci nie zostaje przy tym radykalnie przeciwstawiona temu, co obiektywne - obraz świata przedstawionego jest uzależniony od egzystującego $\mathrm{w}$ nim podmiotu.

\subsection{INTERFERENCJA FOKALIZACJI ZEWNĘTRZNEJ I FOKALIZACJI WEWNĘTRZNEJ}

$\mathrm{Na}$ poziomie narracyjnym najbardziej wyrazistą cechą mowy pozornie zależnej jest brak jasnych wskaźników przypisujących tekst bohaterowi utworu. $\mathrm{O}$ ile podmiotem wypowiedzi w mowie zależnej jest narrator, a w mowie niezależnej - bohater, o tyle w przypadku mowy pozornie zależnej sytuacja jest znacznie bardziej skomplikowana. Wypowiedź bohatera nie zostaje formalnie oddzielona od wypowiedzi narratora.

W filmie również wykształciły się pewne konwencje, mające wskazywać na to, że widz ma do czynienia z percepcją lub świadomością postaci. Za Davidem Bordwellem i Kristin Thompson wyróżniam dwa rodzaje subiektywizacji: percepcyjną, dotyczącą cielesnego odbioru rzeczywistości przez bohatera (fizycznego punktu widzenia lub słyszenia) oraz mentalną, obejmującą 
wspomnienia, przywidzenia czy fantazje postaci ${ }^{18}$. Najpopularniejszym środkiem subiektywizacji percepcyjnej są tzw. ujęcia z punktu widzenia (point-of-view shots). Ich struktura jest zazwyczaj podobna, choć może ulegać rozmaitym wariacjom: kamera pokazuje twarz bohatera, a w kolejnym (lub w poprzednim) ujęciu przedmiot jego spojrzenia. Analogiczny zabieg bywa często stosowany także w przypadku subiektywizacji mentalnej: w jednym ujęciu widzimy twarz bohatera, a $w$ drugim treść jego wizji wewnętrznej. Można powiedzieć, że ramy narracyjne ${ }^{19}$, takie jak zbliżenie twarzy, spełniają funkcję analogiczną do cudzysłowów oraz myślników w mowie niezależnej - dzięki nim płaszczyzna subiektywnych doznań bohatera zostaje wyraźnie wyodrębniona $\mathrm{z}$ narracji utworu ${ }^{20}$. W narracji subiektywnej zapośredniczonej konwencjonalne ramy narracyjne albo w ogóle nie występują, albo ich status jest nieoczywisty.

Właśnie z taką sytuacją mamy do czynienia w „Tańczącym jastrzębiu”. Dobrym przykładem może być scena rozgrywająca się na uczelni. Toporny zostaje wówczas oskarżony przez jedną $\mathrm{z}$ koleżanek o to, że zataił $\mathrm{w}$ ankiecie fakty i nie ujawnił swojego udziału w wojnie. Konstrukcja tej sceny jest szczególna. W trakcie rozmowy Toporny i dziewczyna usytuowani są na dwóch krańcach rzędu ławek, dość daleko od siebie. Gdyby Królikiewicz zdecydował się nadać tej scenie wymiar bezpośrednio subiektywny, pokazałby kobietę z perspektywy Topornego, a więc z dużego dystansu. Tymczasem rozmowa ukazywana jest z zaskakujących punktów widzenia. Kiedy kobieta mówi do Topornego, przedstawiana jest w coraz bliższych planach - od planu średniego po zbliżenie - którym towarzyszy stopniowe rozmazywanie tła. Obraz bohaterki jest nieco zdeformowany, ponieważ Królikiewicz oraz operator filmu Zbigniew Rybczyński zdecydowali się na użycie odpowiednich obiektywów. Nietypowość tych ujęć jest spotęgowana przez fakt, że zwracając się do Topornego, dziewczyna patrzy przez pewien czas prosto $w$ kamerę. Widz odnosi wrażenie, że kamera "tkwi w oczach" bohatera, mimo że fizycznie znajduje się on w zupełnie innym miejscu. Użycie odpowiednich obiektywów

\footnotetext{
${ }^{18} \mathrm{D}$. Bordwell, K. Thompson, Film art. Sztuka filmowa. Wprowadzenie, thum. zbiorowe, Warszawa 2010, s. 106.

${ }^{19} \mathrm{Na}$ temat ram modalnych zob.: E. Biały, Narracja a rama modalna dzieła filmowego - uwagi analityczne, [w:] M. Hendrykowski (red.), Z zagadnień stylu i kompozycji w filmie współczesnym, Poznań 1982, s. 7-16.

${ }^{20}$ Oczywiście umieszczenie w tekście cudzysłowów i myślników - znaków należących do formalnych cech kultury piśmiennej - nie należy do kompetencji narratora, który bardzo rzadko odpowiada za graficzny zapis narracji (wyjątkiem może być np. proza epistolarna). Są one jednak graficznym znakiem zmiany perspektywy, którą narrator sygnalizuje.
} 
oraz bliskich planów pozwala na wykreowanie wrażenia osaczenia, odczuwanego przez mężczyznę. Ujęcia pojawiające się, gdy Toporny odpowiada na zarzuty, przedstawiane są dla odmiany $\mathrm{z}$ zupełnie innego punktu widzenia. Kamera pokazuje wówczas część biblioteki z góry, $\mathrm{z}$ tzw. ptasiej perspektywy - bohater $w$ ogóle nie jest obecny $w$ kadrze. Tego niestandardowego punktu widzenia nie można przypisać żadnej z postaci. Większość obrazu zajmuje wówczas monumentalny regał $\mathrm{z}$ książkami, na tle którego ludzie wydają się jedynie małymi punkcikami. Taka kompozycja kadru oddaje poczucie alienacji Topornego: znajduje się on w obcej, nieprzyjaznej i przytłaczającej przestrzeni. Wydaje się, że przestrzeń pozakadrowa nie pełni tu jedynie takiej funkcji, jaką zwykle przypisywał jej Królikiewicz. Chodzi tu nie tylko o demokratyzację odbioru ${ }^{21}$, lecz także o reprezentację przeżyć głównego bohatera, który czuje się wykluczony, nieznaczący i zmarginalizowany, dlatego „wypada” poza kadr. Narracja tej sceny została zsubiektywizowana dzięki użyciu szeregu środków formalnych, ale nie zostaje w niej zaznaczone, że mamy do czynienia $\mathrm{z}$ fokalizacją Topornego. Brak ram narracyjnych może zachęcać widza do zadawania pytań: kto tak naprawdę percypuje w filmie? Czy narracja jest bezpośrednim odwzorowaniem odczuć Topornego? Są to wątpliwości w pewien sposób analogiczne do pytania „kto mówi (ale także myśli, percypuje) w tekście?", pojawiającego się przy okazji mowy pozornie zależnej. Językoznawcy i literaturoznawcy do dziś spierają się, czy mowa pozornie zależna w sposób bezpośredni odtwarza mowę i percepcję bohatera, czy też jest jedynie ich imitacją, dokonaną przez „wyższą" instancję narracyjną 22 .

W mowie pozornie zależnej narrator oddaje perspektywę bohatera, ale pozostaje nadal bezpośrednim nadawcą przekazu i może (jako fokalizator zewnętrzny) zawrzeć w tekście własne stanowisko wobec „punktu widzenia” postaci. Niejednoznaczna relacja pomiędzy dwoma podmiotami tekstowymi z różnych poziomów narracji skłaniała badaczy do przekonania o dwugłosowości mowy pozornie zależnej. Autorem najbardziej znanej koncepcji jest Walentin Wołoszynow, rosyjski literaturoznawca, uważający, że w „niewłaściwej mowie niezależnej” zachodzi interferencja, nakładanie się języka nar-

\footnotetext{
${ }^{21} \mathrm{Na}$ temat przestrzeni pozakadrowej w kinie Królikiewicza zob.: P. Kletowski, P. Marecki, Królikiewicz. Pracuję dla przyszłości, Kraków 2011, s. 33-37; G. Królikiewicz, Przestrzeń filmowa poza kadrem, [w:] idem, Off, czyli hipnoza kina, Łódź 1992, s. 16-21.

${ }^{22}$ Zob. W. Tomasik, Od Bally'ego do Banfield i dalej: sześć rozpraw o „mowie pozornie zależnej”, Bydgoszcz 1992.
} 
ratora oraz języka postaci ${ }^{23}$. Interferencja językowa służy konfrontacji dwóch różnych perspektyw, dlatego, używając pojęć współczesnej narratologii, można powiedzieć, że nie ogranicza się do poziomu narracji, lecz obejmuje także fokalizację. Jak pisze Wołoszynow:

Niewłaściwa mowa niezależna w ogóle nie wyraża biernego wrażenia wywołanego wypowiedzią cudzą, lecz wyraża aktywne ustosunkowanie się, bynajmniej nie sprowadzające się do zamiany pierwszej osoby na trzecią, lecz wnoszące do cudzej wypowiedzi własne akcenty, które tu zderzają się i interferują z akcentami słowa cudzego $^{24}$.

Przejawem dwugłosowości mowy pozornie zależnej może być ironia ${ }^{25}$. W często cytowanym w tym kontekście zdaniu z „Pani Bovary”: „Lubiła chorą owieczkę, Przenajświętsze Serce przebite ostrymi strzałami i biednego Jezusa, który upada pod ciężarem krzyża”26, zwroty takie jak „chora owieczka” czy „biedny Jezus” wydają się przynależeć do słownika Emmy, ale jednocześnie można się $\mathrm{w}$ nich dopatrzyć ironicznego stosunku narratora do bohaterki.

"Wielogłosowośćc mowy pozornie zależnej może znaleźć swój odpowiednik również w narracji subiektywnej zapośredniczonej. Za przykład niech posłuży pierwsza scena „Palacza zwłok” (1968) Juraja Herza, czechosłowackiego filmu, rozgrywającego się latach 30 . XX w. Główny bohater, pracownik praskiego krematorium Karl Kopfrkingl (Rudolf Hrušínský) wygłasza w zoo monolog skierowany do żony. Kopfrkingl wspomina pierwsze spotkanie z wybranką serca, opowiada o łaskawości natury i samokrytycznie przyznaje, że dotychczas robil za mało dla rodziny. Scena ta pokazywana jest w sposób bardzo nietypowy: widzimy jedynie fragmenty twarzy bohaterów (usta, oczy, czoło, etc.), które zestawiane są z ujęciami przedstawiającymi zwierzęta zamknięte w klatkach. Kompozycja kadrów oraz montaż zastosowany $w$ tej scenie wprowadzają element dysonansu i każą z nieufnością podchodzić do słów mężczyzny. Jak się później okaże, Kopfrkingl jest zimnym i wyrachowanym hipokrytą, który bez wahania podejmie współpracę z faszystami i zamorduje własną rodzinę. Ujęcia przedstawiające fragmenty twarzy bohaterów $\mathrm{w}$ dużych zbliżeniach korespondują ze sposobem patrzenia na rzeczywistość

\footnotetext{
${ }^{23} \mathrm{~W}$. Wołoszynow, Z historii form wypowiedzi w konstrukcjach języka, przeł. Z. Saloni, [w:] Rosyjska szkoła stylistyki, oprac. M.R. Mayenowa, Warszawa 1970, s. 435.

${ }^{24}$ Ibidem, s. 468.

${ }^{25}$ Ironię w mowie pozornie zależnej analizuje Zofia Mitosek: Z. Mitosek, Co z tą ironią??, Gdańsk 2013.

${ }^{26}$ G. Flaubert, Pani Bovary, tłum. A. Micińska, Warszawa 1992, s. 45.
} 
przez mężczyznę, który nie postrzega istot ludzkich jako autonomicznych całości. Ciało ludzkie jest dla Kopfrkingla jedynie przedmiotem, który bardzo łatwo można zdekomponować - na przykład w piecach kremacyjnych, sumiennie przez niego obsługiwanych. Równie znaczące jest zastosowanie montażu, kojarzącego głównego bohatera ze zwierzętami, na które patrzy: zmarszczka na czole mężczyzny przypomina wizualnie kontury łusek na skórze węża, rzęsy - wąsy tygrysa etc. Narracja wizualna umożliwia widzowi wejście „w skórę” Karla, ale jednocześnie każe się zdystansować wobec jego perspektywy - fokalizacji wewnętrznej nieustannie towarzyszy fokalizacja zewnętrzna. $\mathrm{O}$ ile w literackiej mowie pozornie zależnej ironia wynika z prześmiewczego odtwarzania „językowego obrazu świata" bohatera, o tyle w filmie nakierowana jest raczej na psychologiczne odczuwanie rzeczywistości przez postać.

Nieograniczona ramami modalnymi subiektywność bohatera może modelować narrację $\mathrm{w}$ różnoraki sposób - na tę swobodę wskazuje słowo free $\mathrm{w}$ angielskiej nazwie mowy pozornie zależnej (free indirect discourse). W narracji subiektywnej niezapośredniczonej nieustannie zmienia się charakter i natężenie fokalizacji wewnętrznej, a odczucia bohatera mogą być reprezentowane w sposób metaforyczny i zawoalowany. Subiektywność postaci jest poddawana refleksji, a nie traktowana jako gotowa tożsamość, którą narracja mogłaby w sposób bezpośredni ukazać. Efektem takiego ukształtowania jest aktywizacja odbiorcy, który, skonfrontowany $\mathrm{z}$ niekonwencjonalną formą przedstawienia, musi podjąć interpretację, zastanowić się nad znaczeniem środków zastosowanych $\mathrm{w}$ dziele oraz nad konstrukcją podmiotu filmowego. Do refleksji skłania również nieoczywista relacja pomiędzy perspektywą bohatera a perspektywą nadrzędnej świadomości narracyjnej. Relacja ta może się wahać pomiędzy całkowitą identyfikacją a ironicznym dystansem ${ }^{27}$. W jaki sposób zaznaczony jest w narracji „Palacza zwłok” dystans wobec wizji świata bohatera? Jak interpretować enigmatyczne, silnie zsubiektywizowane fragmenty „Tańczącego jastrzębia”? Analizy ogniskujące się wokół pytań uruchamianych przez kategorię narracji subiektywnej zapośredniczonej mogą rzucić nowe światło na grupę filmów, w których relacja pomiędzy subiektywnym doświadczeniem bohatera a kształtem narracji jest nieoczywista. Nie są to bynajmniej zagadnienia przebrzmiałe i wygasłe wraz $z$ kinem ekspe-

${ }^{27}$ Warto wspomnieć, że analizując literacką mowę pozornie zależną, Anna Sobolewska wyróżniła dwie podstawowe tendencje, określające typ relacji obydwu podmiotów tekstowych: są to identyfikacja i karykaturyzacja. Zob. A. Sobolewska, Polska proza psychologiczna (1945-1950), Wrocław 1979. 
rymentującego modernizmu: o narracji subiektywnej zapośredniczonej można także mówić w wypadku takich dzieł, jak „Urodzeni mordercy” Olivera Stone'a.

Podsumowując: zarówno narracja literacka, jak i narracja filmowa implikują obecność pewnej nadrzędnej instancji, przedstawiającej elementy fabuły $z$ określonego "punktu widzenia” - można ją nazwać fokalizatorem zewnętrznym, podmiotem percepcji czy też perspektywą narratora. Choć w przypadku filmu instancja ta jest niespersonalizowana i manifestuje się wyłącznie poprzez rozmaite strategie oraz elementy narracyjne, widz może odbierać ją jako podmiotową, zwłaszcza wtedy, kiedy jej obecność silnie zaznacza się w tekście. Kiedy perspektywa ta zostaje utożsamiona z perspektywą bohatera - tak, jak w przypadku strumieni świadomości - mamy do czynienia z bezpośrednią narracją subiektywną. Inaczej dzieje się w narracji subiektywnej zapośredniczonej, w której narracja nie tyle odwzorowuje, ile imituje percepcję bohatera, posługuje się jego sposobem myślenia oraz postrzegania świata. Narracja subiektywna zapośredniczona pod wieloma względami przypomina literacką mowę pozornie zależną, dlatego można mówić $\mathrm{w}$ tym wypadku o różnych realizacjach tej samej, transmedialnej figury, opartej na niebezpośredniej subiektywizacji przekazu oraz niejednoznacznej relacji pomiędzy bohaterem utworu a świadomością narracyjną. Jednocześnie jednak medium filmowe, tworzące reprezentację niewerbalnego doświadczenia bohatera, znacząco ją modyfikuje, co jest spowodowane przede wszystkim jego wielosemiotycznym charakterem. Wyodrębnienie narracji subiektywnej zapośredniczonej może nie tylko wzbogacić komparatystykę intermedialną, lecz także zwrócić uwagę na stricte filmowe zagadnienia, nieopisane dotychczas $\mathrm{w}$ wyczerpujący sposób.

\section{Robert Birkholc \\ THE MEDIATED SUBJECTIVE NARRATIVE. ON “FREE INDIRECT SPEECH" IN FILM}

\section{Summary}

The paper is devoted to mediated subjective narrative which, according to the author, constitutes the filmic manifestation of a transmedial textual figure which functions in literature as free indirect speech. Theorists of cinema. such as Pier Paolo Pasolini or Gilles Deleuze, did address the cinematic free indirect discourse on several 
occasions, but a methodologically consistent description of the issue is still lacking. The author suggests two markers of that category: 1) subjectivization of communication on a stylistic level and 2) interference of external and internal focalization. Here, the manner in which perception and consciousness of the protagonist are manifested in the narrative is considered a distinctive trait of that textual figure. Unlike the "classic" subjective narration, mediated subjective narrative not so much reproduces but imitates the perception of the protagonist; it does not create the illusion of direct access to their inner world but underscores the mediation of a different subject in communicating mental states of the characters. Consequently, in pictures such as The Dancing Hawk or The Cremator, the relationship between the viewpoint of the protagonist and the perspective of the superordinate narrative consciousness is equivocal and can oscillate between identification and ironic distance. In many respects, mediated subjective narrative resembles the free indirect discourse in literature, but the medium of film modifies it substantially, chiefly due to the its multisemiotic nature. This description of mediated subjective narrative introduces an order into the methodological chaos associated with the haphazard use of the notion of "cinematic free indirect speech", but also casts a new light on representations of subjectivity in cinema.

\section{Bibliografia}

Bal M., Narratologia. Wprowadzenie do teorii narracji, Kraków 2012.

Bialy E., Narracja a rama modalna dzieła filmowego - uwagi analityczne, [w:] M. Hendrykowski (red.), Z zagadnień stylu i kompozycji w filmie współczesnym, Poznań 1982, s. 7-16.

Bordwell D., Thompson K., Film art. Sztuka filmowa. Wprowadzenie, Warszawa 2010.

Chatman S., Coming To Terms. The Rhetoric of Narrative in Fiction and Film, London 1990.

Deleuze G., Kino. Obraz-ruch. Obraz-czas, Gdańsk 2008.

Deleyto C., Focalisation in Film Narrative, Atlantis 13, 1-2, 1991, s. 159-177.

Elsaesser T., Hagener M., Teoria filmu: Wprowadzenie przez zmysły, Kraków 2015.

Flaubert G., Pani Bovary, tłum. A. Micińska, Warszawa 1992.

Genette G., Narrative Discourse. An Essay in Method, New York 1980.

Gunning T.D., W. Griffith and the Origins of American Narrative Film: The Early Years at Biograph, Chicago 1991.

Hernadi P., Dual Perspective: Free Indirect Discourse and Related Techniques, Comparative Literature 24, 1, 1972, s. 32-43.

Jahn M., Windows of Focalization: Deconstructing and Reconstructing a Narratological Concept, Style 2, 1996, s. 241-267.

Kletowski P., Marecki P., Królikiewicz. Pracuję dla przyszłości, Kraków 2011.

Królikiewicz G., Off, czyli hipnoza kina, Łódź 1992.

Lebkowska A., Pojęcie fokus w narratologii - problemy i inspiracje, [w:] J. Bartmiński, S. Niebrzegowska-Bartmińska, R. Nycz (red.), Punkt widzenia w tekście i w dyskursie, Lublin 2004, s. 219-238.

Markiewicz H., Teorie powieści za granicą, Warszawa 1995.

Michera W., Piękna jako bestia. Przyczynek do teorii obrazu, Warszawa 2010. 
Mitosek Z., Co z tą ironią?, Gdańsk 2013.

Nelles W., Getting Focalization into Focus, Poetics Today 2 (11), 1990, s. 365-382.

Orr J., Contemporary Cinema, Edinburgh 2003.

Pasolini P.P., Po ludobójstwie. Eseju o języku, polityce i kinie, red. M. Werner, Warszawa 2012. Płażewski J., Język filmu, Warszawa 2008.

Przylipiak M., Kino stylu zerowego, Gdańsk 1994.

Przylipiak M., Narrator literacki, „narrator” filmowy, [w:] J. Trzynadlowski (red.), Problemy poznawania dzieła filmowego, Wrocław 1990, s. 63-81.

Przylipiak M., O subiektywizacji narracji filmowej, Studia Filmoznawcze VII, 1987, s. 239-256.

Rembowska-Płuciennik M., W cudzej skórze. Fokalizacja zmysłowa a literackie reprezentacje doświadczeń sensualnych, Ruch Literacki 6, 2006, s. 51-67.

Schwartz L.-G., Typewriter: free indirect discourse in Deleuze's Cinema, SubStance 3 (34), 2005, s. 107-135.

Sobolewska A., Polska proza psychologiczna (1945-1950), Wrocław 1979.

Tomasik W., Od Bally'ego do Banfield i dalej: sześć rozpraw o "mowie pozornie zależnej”, Bydgoszcz 1992.

Verstraten P., Film Narratology, Toronto 2009.

Wilson G., Narration in Light, Studies in Cinematic Point of View, London 1992.

Wołoszynow W., Z historii form wypowiedzi w konstrukcjach języka, [w:] Rosyjska szkoła stylistyki, oprac. M.R. Mayenowa, Warszawa 1970, s. 451-477. 